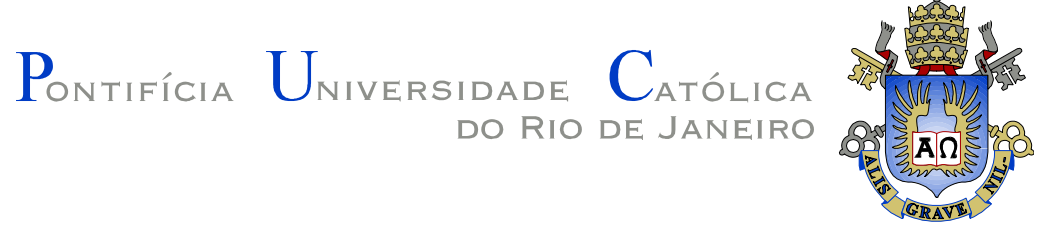

Maria Manoella Beaklini Baffa

\title{
A forma da metafísica: sobre a história na obra tardia de Heidegger
}

Tese apresentada ao Programa de Pós-graduação do Departamento de Filosofia da PUC-Rio como parte dos requisitos para obtenção do título de Doutor em Filosofia.

Orientador: Eduardo Jardim de Moraes

Rio de Janeiro, setembro de 2005 


\section{Pontifícia $U_{\text {niversidade }}$ Católica $_{\text {ate }}$

Maria Manoella Beaklini Baffa

A forma da metafísica: sobre a história na obra tardia de Heidegger

Tese apresentada como requisito parcial para obtenção do grau de Doutor pelo Programa de Pós-graduação em Filosofia do Departamento de Filosofia do Centro de Teologia e Ciências Humanas da PUC-Rio. Aprovada pela Comissão Examinadora abaixo assinada.

Prof. Eduardo Jardim de Moraes Orientador

Departamento de Filosofia - PUC-Rio

Prof. André de Macedo Duarte Departamento de Filosofia - UFPR

Prof. Edgar de Brito Lyra Departamento de Filosofia - PUC-Rio

Profa.Kátia Muricy Rodrigues Departamento de Filosofia - PUC-Rio

Profa. Nelcy Nascimento Departamento de Filosofia - UERJ

Prof. Paulo Fernando C. de Andrade Coordenador Setorial do Centro de Teologia e Ciências Humanas - PUC-Rio

Rio de Janeiro, 23 de setembro de 2005 
Todos os direitos reservados. É proibida a reprodução total ou parcial do trabalho sem autorização da universidade, do autor e do orientador.

\section{Maria Manoella Beaklini Baffa}

Graduou-se em comunicação social pela PUC-Rio em 1997. Obteve, em 2001, o título de mestre em filosofia, com uma dissertação intitulada "Heidegger e o sentido da história". Participou de diversos congressos, colóquios e seminários, abordando temas ligados à fenomenologia e à filosofia da história moderna e contemporânea. Tendo recebido uma bolsa sanduíche da Capes, realizou pesquisas na Universidade de Nice entre 2002 e 2003. Obteve, nesta mesma universidade, um Diplôme d'Etudes Approfondies em filosofia e história das idéias, sob a orientação da Profa. Françoise Dastur. É professora dos cursos de especialização em filosofia da PUC-Rio.

\section{Ficha Catalográfica}

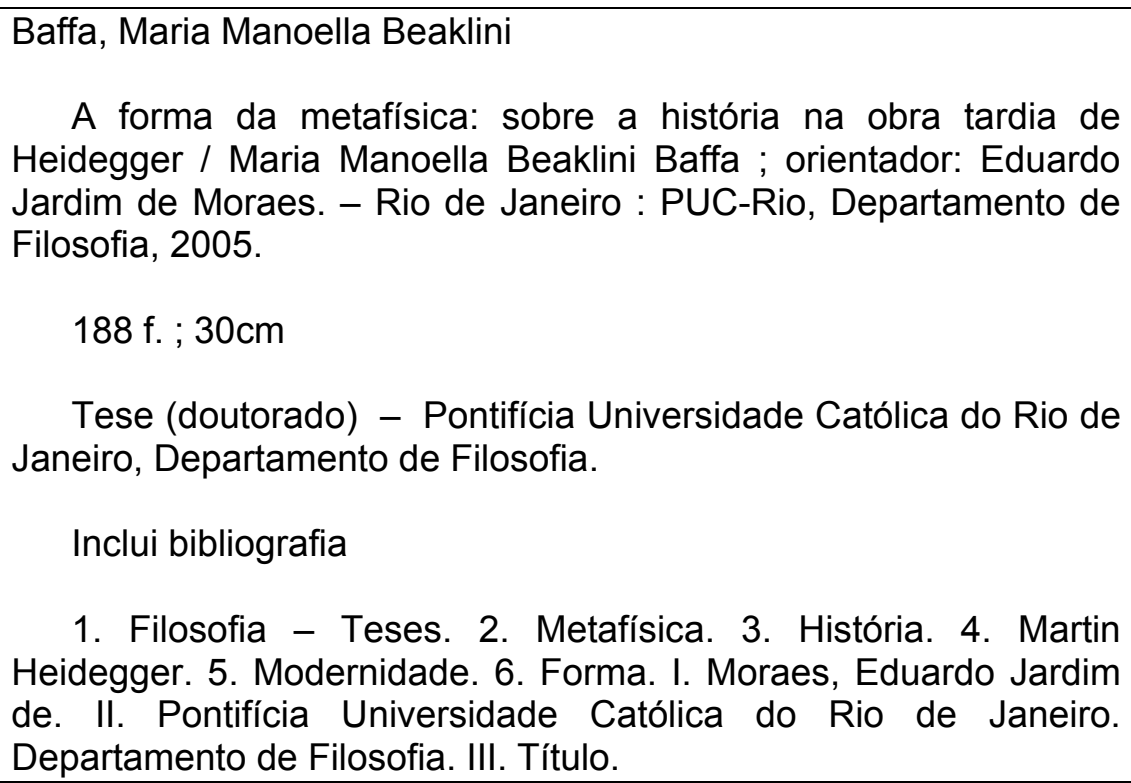

A forma da metafísica: sobre a história na obra tardia de Heidegger / Maria Manoella Beaklini Baffa ; orientador: Eduardo Jardim de Moraes. - Rio de Janeiro : PUC-Rio, Departamento de Filosofia, 2005.

188 f. ; $30 \mathrm{~cm}$

Tese (doutorado) - Pontifícia Universidade Católica do Rio de Janeiro, Departamento de Filosofia.

Inclui bibliografia

1. Filosofia - Teses. 2. Metafísica. 3. História. 4. Martin Heidegger. 5. Modernidade. 6. Forma. I. Moraes, Eduardo Jardim de. II. Pontifícia Universidade Católica do Rio de Janeiro. Departamento de Filosofia. III. Título. 


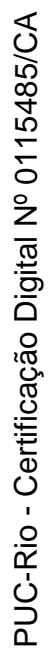

À memória de Antonio Abranches, 


\section{Agradecimentos}

Ao Eduardo Jardim.

Aos professores do Departamento de Filosofia da PUC-Rio.

Ao CNPq, pela bolsa de doutorado concedida.

À Capes, pela bolsa "sanduíche" concedida entre 2002 e 2003.

Aos amigos Edgar Lyra, Andrea Bieri, Filipe Ceppas, Tito Marques Palmeiro e Pedro Duarte.

A Françoise Dastur e Eliane Escoubas.

Ao André Duarte.

A Benoit Guilielmo e Alexandre Martin.

A Myriam, Altair, Marianna e Maria Pia.

A Jean-Baptiste. 


\section{Resumo}

Em 1927, Heidegger dedica um dos capítulos finais de Ser e tempo a mostrar o "nexo" entre a sua exposição do problema da historicidade e as pesquisas de Wilhelm Dilthey. O capítulo consiste numa série de citações de trechos da correspondência entre Dilthey e um certo Conde Yorck, em que as cartas citadas, curiosamente, são apenas as deste último. O que Heidegger encontra nessas cartas é a afirmação de que o pensamento histórico tradicional se atém, "com imensa força, a determinações puramente oculares". O que ele descobre na crítica do Conde Yorck à tradição da historiografia é que o figurável, o imagético, o "esteticamente construído", literalmente, o espetacular, são o objeto historicamente privilegiado da reflexão - histórica ou filosófica - sobre a história. Cerca de trinta anos mais tarde, é Heidegger quem escreve uma carta a Ernst Jünger, dizendo que em seu livro $O$ Trabalhador Jünger teria dado à forma um "estatuto sagrado". No intervalo, o projeto de fundamentar existencialmente a historiografia foi abandonado e Heidegger passa a interrogar o que se decide na história do Ocidente sob o nome de "metafísica". Nessa nova posição, vemos se elaborar a perspectiva de que uma cumplicidade bi-milenar entre a forma, a idéa e o ser mobiliza o pensar e o fazer ocidentais. Heidegger confiará então a Jünger que a forma é "potência metafísica". A tese parte dessas duas indicações principais para pensar o que está em jogo nessa potência "ocular" que Heidegger identifica na (e à) história da tradição. Em seguida, ela coloca a questão sobre o sentido e a possibilidade de uma superação do recurso metafísico à imagem.

\section{Palavras-chave}

Metafísica; história; Martin Heidegger; modernidade; forma 


\section{Résumé}

En 1927, Heidegger consacre l'un des derniers chapitres de Etre et temps à exposer le «lien» entre ses propres développements concernant le problème de l'historicité et les investigations menées par Wilhelm Dilthey sur ce même sujet. Le chapitre se compose d'une suite de citations de passages de la correspondance entre Dilthey et son ami le Comte Yorck von Wartenburg, mais les lettres reprises par Heidegger ne sont que celles du Comte Yorck. Il y reconnait l'affirmation que la pensée historique traditionnelle s'attache encore de façon profonde à des « déterminations purement oculaires ». Ce que Heidegger découvre dans la critique du Comte Yorck à la tradition de l'historiographie, c'est l'idée que le figuratif, l'imaginable, «l'esthétiquement construit », ou littéralement le spectaculaire sont des objets historiquement privilégiés par la réflexion - historique ou philosophique - sur l'histoire. Presque trente ans plus tard, c'est encore dans le contexte d'un échange épistolaire que nous verrons s'élaborer sous la plume de Heidegger une critique au privilège de la figure. Dans une lettre alors adressée à Ernst Jünger, il reprochera à son interlocuteur d'avoir conféré à la forme « un statut sacré ». Entre-temps, le projet annoncé dans Etre et temps de fonder l'historiographie sur une compréhension propre de l'existence a été abandonné. Il s'agit alors d'interroger la portée de cette tradition que Heidegger désignera du nom de "métaphysique». A la base de cette nouvelle position, c'est une complicité fondamentale entre la forme, l'idée et l'être qu'il s'efforcera de montrer, laquelle aurait mobilisé la pensée occidentale depuis deux millénaires. Heidegger le confiera à Jünger : « la forme est puissance métaphysique ». La thèse partira de ces deux indications principales pour penser ce qui est en cause dans cette "puissance oculaire» que, depuis les années vingt, Heidegger semble identifier à l'histoire de l'Occident. Ensuite nous poserons la question sur le sens et la possibilité d'un dépassement du recours métaphysique à l'image.

\section{Mots-clefs}

Métaphysique; histoire, Martin Heidegger, modernité, forme 


\section{Sumário}

$\begin{array}{ll}\text { Introdução } & 11\end{array}$

1. A fabricação da História :

da entronização e do declínio de um conceito 26

Uma idéia da história 30

Para educar a humanidade $\quad 34$

A Idéia na história $\quad 38$

Fatos e fontes $\quad 44$

Crítica da razão histórica $\quad 47$

Da história à vida $\quad 51$

Da vida à história $\quad 54$

Da visibilidade da história $\quad 57$

2. A forma da metafísica e a travessia da história 67

Do quê e do como $\quad 73$

A paidéia platônica e o pôr em forma da verdade $\quad 75$

A metafísica entra em cena $\quad 78$

Um novo modo de (não) ver $\quad 81$

Uma marcha, um desvio, uma volta $\quad 84$

O motu continuum da transcendência $\quad 88$

Um sistema de equivalências? $\quad 91$

Uma indecisão originária $\quad 93$

3. De um extremo a outro da metafísica: "o mesmo

essencialmente transformado" 100

$\begin{array}{lr}\text { Diferentes posições, novas configurações } & 102\end{array}$

Breves inventários 109

$\begin{array}{lr}\text { A verdade imperial } & 112\end{array}$

Um deus que dá ordens 115

$\begin{array}{ll}\text { Que a verdade e a justiça... se façam } & 118\end{array}$

Operari, facere, agere: "o real incluído no procedimento do agir" 123

Uma metafísica da manufatura? 128

Uma dobra sobre si: do apequenamento metafísico do mundo 136

4. O mundo feito imagem 142

$\begin{array}{ll}\text { Para onde tudo retorna } & 145\end{array}$

Weltbild e Weltanschauung: a antropologia em sua última forma 148

$\begin{array}{ll}\text { Maquinação e vivência } & 153\end{array}$ 
Vontade e sistema

A fisionomia do novo homem

165

Uma antiga inscrição

173

Considerações finais

181

Referências bibliográficas 
"Teoria da imaginação. É a faculdade de plasticizar." Novalis, Das allgemeine Brouillon, 698

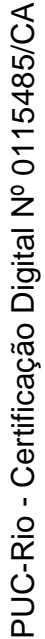

